\title{
Is Risk Malignancy Index a Useful Tool for Predicting Malignant Ovarian Masses in Developing Countries?
}

\author{
Aliya B. Aziz and Nida Najmi \\ Department of Obstetrics and Gynaecology, Aga Khan University Hospital, Karachi 74800, Pakistan \\ Correspondence should be addressed to Aliya B. Aziz; azizaliya@hotmail.com
}

Received 28 March 2015; Accepted 14 June 2015

Academic Editor: Enrique Hernandez

Copyright ( 2015 A. B. Aziz and N. Najmi. This is an open access article distributed under the Creative Commons Attribution License, which permits unrestricted use, distribution, and reproduction in any medium, provided the original work is properly cited.

\begin{abstract}
Introduction. Risk of Malignancy Index (RMI) is widely studied for prediction of malignant pelvic masses in Western population. However, little is known regarding its implication in the developing countries. The objective of this study is to determine how accurately the RMI can predict the malignant pelvic masses. Materials and Methods. The study is a retrospective review of patients attending the gynecological clinic between January 2004 and December 2008 with adnexal masses. Information on demographic characteristics, ultrasound findings, menopausal status, CA125, and histopathology was collected. RMI score for each patient in the study group was calculated. Results. The study group included a total of 283 patients. Analysis of the individual parameters of RMI revealed that ultrasound was the best predictor of malignancy with a sensitivity, specificity, and positive likelihood ratio of $78.3 \%, 81.5 \%$, and 4.2 , respectively. At a standard cut-off value of 250 , RMI had a positive likelihood ratio of 8.1 , while it was 6.8 at a cut-off of 200, albeit with comparable sensitivity and specificity. Conclusion. RMI is a sensitive tool in predicting malignant adnexal masses. A cut-off of 200 may be suitable in developing countries for triaging and early referral to tertiary care centers.
\end{abstract}

\section{Introduction}

Ovarian masses are a frequent cause of gynecological consults and are often detected during imaging studies or exploratory surgery for evaluation of abdominal or pelvic pain syndromes. They occur across age groups and could result from benign or malignant disease. With more than 250,000 new cases reported every year, ovarian malignancies represent the fourth commonest cause of cancer deaths worldwide [1]. They also have the lowest 5-year survival rate (30-50\%) among all gynecological cancers [2]. A recent report indicated an increasing incidence of ovarian cancers in the developing world, compared to the developed countries [3].

Early identification of ovarian carcinomas and referral to a gyneco-oncologist can facilitate accurate staging of the disease and optimal cytoreductive treatment, enhancing patient survival $[4,5]$. Histopathology remains the diagnostic gold standard for this cancer, and a definitive biomarker has not been identified yet. Risk of Malignancy Index (RMI), which considers the serum CA125 level, menopausal status, and ultrasonographic findings in predicting malignant pelvic masses, is widely employed in the developed countries [6]. However, its utility in risk prediction in the developing countries is currently unknown.

The present study evaluated how accurately the RMI can predict the risk of malignant pelvic masses, among patients with an ovarian mass.

\section{Material and Methods}

After the approval of our institutional review board we conducted a retrospective review of the case files of patients with adnexal masses who attended the Gynecological Clinic at the Aga Khan University, Karachi, Pakistan, between January 2004 and December 2008. The International Classification of Diseases, 9th Revision, Clinical Modification (ICD-9-CM) criteria were used to identify adnexal masses. Patients with advanced disease were excluded from the study. We collected information on demographic characteristics, ultrasonographic findings, menopausal status, serum CA125 level, and histopathology. The RMI for each patient was calculated using the standard formula [6]. 


\section{Results}

3.1. Demographic Data. The study group consisted of a total of 283 patients. The age of the patients varied from 8 to 85 years (mean, 38.6 years). Premenopausal patients predominated in our study with $227(80.8 \%)$ cases, while 54 (19.2\%) of the affected patients were in the postmenopausal group.

3.2. Ultrasonography Findings. Two hundred and seven (73.7\%) patients had a transabdominal ultrasonography for diagnosis, while transvaginal ultrasonography detected the disease in $74(26.3 \%)$ cases. Table 1 shows the summary of ultrasound findings in our patients.

3.2.1. Laterality of Lesion. The investigation revealed a unilateral cyst in $252(89.7 \%)$ cases, while 29 (10.3\%) had bilateral cysts.

3.2.2. Loculation. The lesions were multilocular in 166 (59\%) patients and unilocular in 115 (41\%).

3.2.3. Echogenicity. Solid areas were absent in the lesions in $196(69.8 \%)$ patients, while these were detected in $85(30.2 \%)$ patients.

3.2.4. Evidence of Metastasis. The majority of patients (272, $96.8 \%)$ had no evidence of metastasis, while 9 (3.2\%) had metastatic disease.

3.2.5. Presence of Ascites. Ascites was present in only 19 (6.8\%) patients.

3.2.6. Ultrasound Score. We assigned scores of 0 (absence of specific findings), 1 (presence of one finding), or 3 (two or more findings) to the subjects, depending on the ultrasound findings. One hundred and nineteen (42.3\%) cases had an ultrasound score of 1 , while lesions of 88 (31.3\%) and 74 (26.3\%) patients were scored 0 and 3, respectively. Of the $207(73.6 \%)$ patients with an ultrasound score 1, 196 (69.7\%) had benign disease, while $8(2.8 \%)$ and $3(1 \%)$ had malignant and borderline disease, respectively. Seventy-four $(26.3 \%)$ patients in our series had an ultrasound score of 3 , and among them, 41 (14.5\%) had benign, 29 (10.3\%) had malignant, and $4(1.4 \%)$ had borderline disease, respectively.

3.2.7. Ovarian Size. Ovarian size varied from 3 to $73 \mathrm{~cm}$ (mean, $10.5 \mathrm{~cm}$ ).

3.3. Histopathology Findings. As shown in Table 2, 237 $(84.3 \%)$ patients had benign lesions, while $37(13.2 \%)$ had a malignant disease. Seven (2.5\%) patients under 60 years of age had borderline lesions. One hundred and thirty-nine (49.4\%) of the benign tumours occurred in patients aged 20 to 39 years, and $60(21.3 \%)$ cases were in those aged $41-59$ years. Patients aged $\leq 20$ years and $\geq 60$ years reported $24(8.5 \%)$ and $14(4.9 \%)$ cases of benign disease, respectively. Malignant disease peaked in the age group 40-59 years with $21(7.4 \%)$ cases, while $10(3.5 \%), 4(1.4 \%)$, and $2(0.7 \%)$ cases occurred among patients aged $\geq 60$ years, $20-39$ years, and $\leq 20$ years,
TABLE 1: Summary of ultrasound findings in the study.

\begin{tabular}{lcc}
\hline & Frequency & Percentage (\%) \\
\hline Transabdominal scan & 207 & 73.7 \\
Transvaginal scan & 74 & 26.3 \\
\hline Unilateral cyst & 252 & 89.7 \\
Bilateral cyst & 29 & 10.3 \\
\hline Unilocular cyst & 115 & 41.0 \\
Multilocular cyst & 166 & 59.0 \\
\hline Presence of solid areas & 85 & 30.2 \\
Absence of solid areas & 196 & 69.8 \\
\hline Evidence of metastasis present & 9 & 3.2 \\
Evidence of metastasis absent & 272 & 96.8 \\
\hline Presence of ascites & 19 & 6.8 \\
Absence of ascites & 262 & 93.2 \\
\hline Ultrasound score 0 & 88 & 31.3 \\
Ultrasound score 1 & 119 & 42.3 \\
Ultrasound score 3 & 74 & 74 \\
\hline
\end{tabular}

TABLE 2: Distribution of cases in the study.

\begin{tabular}{lcccc}
\hline & $\begin{array}{c}\text { Benign } \\
(\%)\end{array}$ & $\begin{array}{c}\text { Borderline } \\
(\%)\end{array}$ & $\begin{array}{c}\text { Malignant } \\
(\%)\end{array}$ & Total (\%) \\
\hline Histopathology & $237(84.3)$ & $7(2.5)$ & $37(13.2)$ & 281 \\
\hline Age (years) & & & & \\
$\quad \leq 20$ & $24(8.5)$ & $1(0.3)$ & $2(0.7)$ & $27(9.6)$ \\
$20-39$ & $139(49.4)$ & $3(1.0)$ & $4(1.4)$ & $146(51.9)$ \\
$40-59$ & $60(21.3)$ & $3(1.0)$ & $21(7.4)$ & $84(29.8)$ \\
$\geq 60$ & $14(4.9)$ & $0(0)$ & $10(3.5)$ & $24(8.5)$ \\
\hline Premenopausal & $203(72.2)$ & $6(2.1)$ & $18(6.4)$ & $227(80.7)$ \\
Postmenopausal & $34(12.0)$ & $1(0.3)$ & $19(6.7)$ & $54(19.2)$ \\
\hline Ultrasound score 1 & $196(69.7)$ & $3(1.0)$ & $8(2.8)$ & $207(73.6)$ \\
Ultrasound score 3 & $41(14.5)$ & $4(1.4)$ & $29(10.3)$ & $74(26.3)$ \\
\hline CA125 $\geq 35$ & $75(26.6)$ & $4(1.4)$ & $26(9.2)$ & $105(37.3)$ \\
Ca125<35 & $162(57.6)$ & $3(1.0)$ & $11(3.9)$ & $176(62.6)$ \\
\hline RMI groups & & & & \\
$\quad \leq 25$ & $117(41.6)$ & $0(0)$ & $3(1.0)$ & $120(42.7)$ \\
$25.1-249.9$ & $106(37.7)$ & $5(1.7)$ & $14(4.9)$ & $125(44.4)$ \\
$\geq 250$ & $14(4.9)$ & $2(0.7)$ & $20(7.1)$ & $36(12.8)$ \\
\hline
\end{tabular}

respectively. Three cases of borderline disease occurred in the age groups $21-39$ and $40-59$ years, and one (0.3\%) case was in a woman aged $\leq 20$ years, while such lesions were not detected in women $\geq 60$ years. Two hundred and three $(72.2 \%)$ of the 227 premenopausal patients had benign disease, while 18 (6.4\%) had malignant, and $6(2.1 \%)$ had borderline lesions. Among the 54 (19.2\%) postmenopausal patients, 34 (12\%) had benign disease, while $19(6.7 \%)$ and $1(0.3 \%)$ had malignant and borderline disease, respectively.

3.4. Serum CA125 Levels. The serum CA125 levels in the patients varied from 1.2 to $6803 \mathrm{U} / \mathrm{mL}$ (mean, $197 \mathrm{U} / \mathrm{mL}$ ) (Table 2 ). One hundred and seventy-six (62.6\%) patients had a serum CA125 level less than $35 \mathrm{U} / \mathrm{mL}$, while the levels 
TABLE 3: Diagnostic performance of the different RMI cut-offs employed.

\begin{tabular}{|c|c|c|c|c|c|c|}
\hline RMI cut-off value & Sensitivity & Specificity & PPV & NPV & $+\mathrm{LR}$ ratio & $-\mathrm{LR}$ ratio \\
\hline 250 & $54.05(20 / 37)$ & $93.4(228 / 244)$ & $55.5(20 / 36)$ & $93.06(228 / 245)$ & 8.1 & 0.49 \\
\hline 200 & $53.8(21 / 39)$ & $92.2(225 / 244)$ & $52.5(21 / 40)$ & $92.5(225 / 243)$ & 6.8 & 0.50 \\
\hline 150 & $61.5(24 / 39)$ & $89.3(218 / 244)$ & $48.0(24 / 50)$ & $93.5(218 / 233)$ & 5.7 & 0.43 \\
\hline 100 & $66.6(26 / 39)$ & $84.0(205 / 244)$ & $40.0(26 / 65)$ & $94.0(205 / 218)$ & 4.1 & 0.39 \\
\hline
\end{tabular}

TABLE 4: Diagnostic performance of the criteria evaluated.

\begin{tabular}{lcccccc}
\hline & Sensitivity \% & Specificity \% & PPV $(\%)$ & NPV (\%) & +ve likelihood ratio & -ve likelihood ratio \\
\hline RMI $\geq 250$ & $54.05(20 / 37)$ & $93.4(228 / 244)$ & $55.5(20 / 36)$ & $93.06(228 / 245)$ & 8.1 & 0.49 \\
CA125 $\geq 35$ & $70.2(26 / 37)$ & $67.6(165 / 244)$ & $24.7(26 / 105)$ & $93.7(165 / 176)$ & 2.1 & 0.44 \\
Ultrasound score 3 & $78.3(29 / 37)$ & $81.5(199 / 244)$ & $39.1(29 / 74)$ & $96.1(199 / 207)$ & 4.2 & 0.26 \\
Menopause score 3 & $51.3(19 / 37)$ & $85.6(209 / 244)$ & $35.1(19 / 54)$ & $92.0(209 / 227)$ & 3.5 & 0.56 \\
\hline
\end{tabular}

were higher in 105 (37.3\%) patients. Among the patients with CA125 levels greater than $35 \mathrm{U} / \mathrm{mL}, 75$ (26.6\%) had benign disease, 26 (9.2\%) had malignant, and 4 (1.4\%) had borderline lesions. One hundred and sixty-two (57.6\%) patients with CA125 levels less than $35 \mathrm{U} / \mathrm{mL}$ had benign lesions, while 11 (3.9\%) had malignant, and 3 (1\%) had borderline disease.

3.5. RMI. The RMI was calculated according to a standard formula (Jacobs et al., 1990). The RMI scores of the patients varied from 1.9 to 32364 (mean, 601.1 \pm 3196.3) (Table 2). Two hundred and forty-five $(87.1 \%)$ patients had an RMI score less than 250, while 36 (12.8\%) had scores above 250 . Twenty of the patients with RMI scores $\geq 250$ had malignant disease, while 14 had benign and 2 had borderline lesions. Among patients with RMI scores less than 250, 223 (79.3\%) had benign disease, while 17 (6\%) and $5(1.7 \%)$ had malignant and borderline lesions, respectively.

3.6. Risk Stratification Based on RMI Scores. We assessed the distribution of benign, borderline, and malignant ovarian cancers when the patients were categorized based on their RMI scores.

In order to identify the RMI score that was an effective risk predictor, we studied the sensitivity and specificity of RMI scores at four levels, namely, $\leq 100, \leq 150, \leq 200$, and $\leq 250$. The sensitivity, specificity, and positive and negative predictive values of RMI score at each of these levels are summarized in Table 3.

One hundred and twenty (42.7\%) patients had RMI scores $\leq 25$, among whom 117 (41.6\%) had benign disease, 3 (1\%) had malignant disease, and none had borderline lesions. The scores ranged from 25.1 to 249 in 125 (42.7\%) patients. In this group, $106(37.7 \%)$ patients had benign disease and 5 (1.7\%) had borderline disease, while 14 (4.9\%) had malignant disease. In the third group with RMI scores $\geq 250,20$ (7.1\%) had malignant disease, $2(0.7 \%)$ had borderline disease, and 14 (4.9\%) had benign disease.

To find out the RMI score that could most effectively classify the disease, we calculated the sensitivity, specificity, positive predictive value, negative predictive value, and the likelihood ratios at RMI cut-off levels of 100, 150, 200, and
250. A comparison of the diagnostic indices with these cutoffs is shown in Table 3.

As shown in Table 3, an RMI of 250 yielded the ideal combination of sensitivity (54.05), specificity (93.4), positive predictive value (55.5), negative predictive value (93.06), and positive (8.1) and negative (0.49) likelihood ratios. Though cut-offs of 100 and 150 showed higher sensitivity in detecting malignant disease, they had lower specificity, positive predictive value, and likelihood ratios, compared to 250 .

We also compared the diagnostic performance of RMI scores $>250$ against CA125 levels $>35 \mathrm{U} / \mathrm{mL}$, ultrasound score of 3 and menopausal score of 3 . Table 4 summarizes the findings from this analysis. Among the three criteria, an ultrasound score of 3 had the highest sensitivity (78.3\%), while an RMI score $\geq 250$ had the highest specificity (93.4\%). The latter also had the highest positive predictive value of $55.5 \%$, while negative predictive value was highest for an ultrasound score of 3 (96.1\%). The positive likelihood ratio was highest for RMI score $\geq 250$, while a score of 100 had the least negative likelihood ratio (0.39).

\section{Discussion}

About $10 \%$ of women undergo exploratory surgery for evaluation of ovarian masses during their lifetime [7]. Prompt identification of ovarian malignancies and referral to a gyneco-oncologist can enhance the patient survival rates [8], but a single method which can accurately predict ovarian malignancy is still unavailable. Herein we report that the multiparametric RMI score can be a useful tool in prediction of malignant ovarian disease, in low-resource settings.

The mean age of the patients with ovarian mass in our study was 36.87 years (range, 8 to 85 years). This is slightly higher than that reported in a similar study by Akdeniz et al. in 2009 [9].

In our study, $13.2 \%$ of the patients with an ovarian mass had malignant disease. Thirty-five percent of malignancies occurred in postmenopausal patients and $7.9 \%$ among the premenopausal patients. The data seem to agree with earlier reports of similar incidence rates and preponderance in postmenopausal patients [9-12]. 
Ultrasonography is widely appreciated as the best imaging method for evaluation of ovarian pathology. Several groups have reported higher sensitivity, specificity, and positive predictive values for this method (Agarwal et al., 2011, and references therein). In our study, an ultrasound score of 3 had the highest sensitivity (78.3\%) and negative predictive value $(96.1 \%)$ and the least negative likelihood ratio (0.26), among the parameters evaluated.

Several candidate biomarkers and their combinations have been employed in assessing the risk of ovarian malignancies, albeit with varying efficiency [13]. Serum CA125 level is widely appreciated as a useful biomarker for estimating the risk of ovarian cancer, though other gynecological pathology can also increase its levels. Myers et al. [14] have earlier reported sensitivity and specificity of less than $80 \%$, for this marker, in the prediction of ovarian cancers. Simsek et al. (2014) [15] reported a sensitivity of $78.6 \%$ and specificity of $63.5 \%$ for a CA125 cut-off of $35 \mathrm{U} / \mathrm{mL}$. Another report indicated a sensitivity of $88 \%$ and specificity of $97 \%$ for CA125 at a higher cut-off of $88 \mathrm{U} / \mathrm{mL}$ [12]. In our study, CA125 levels $\geq 35 \mathrm{U} / \mathrm{mL}$ had a sensitivity of $70.2 \%$, specificity of $67.6 \%$, positive predictive value of $24.7 \%$, negative predictive value of 93.7, and positive and negative likelihood ratios of 2.1 and 0.44 , respectively. We suggest that a higher prevalence of inflammatory and nonspecific uterine and ovarian pathology might have contributed to elevated CA125 levels in the majority of our patients and thus its low diagnostic performance in the detection of malignant ovarian disease.

Rao (2014) [16] has recently reported higher sensitivity, specificity, and positive and negative predictive values for a postmenopausal score of 3. In our study, this parameter had a higher specificity and negative predictive value, but lower sensitivity and positive predictive values in assessing malignancy risk.

RMI was first proposed by Jacobs et al. and is calculated from the serum CA125 antigen level, menopausal status, and ultrasonographic findings [6]. Several retrospective and prospective studies have reported it to be the best available tool for triage and referral of ovarian malignancies [17, 18]. Its utility as a diagnostic tool depends on the prevalence of malignancy in the study population [15]. We observed a low prevalence of malignancy (13.2\%) among our study group, significantly lesser than some of the earlier reports of $30-43 \%$ $[6,17,19]$.

Jacobs et al. (1990) [6], studying 143 patients, reported a sensitivity of $85.4 \%$ and specificity of $96.9 \%$ for this method, with a cut-off of 200. Subsequently, several groups have reported its superior sensitivity and specificity in estimating the risk of ovarian malignancy, compared to other parameters [19-25]. The RMI cut-offs in many studies ranged from 25 to 250 (reviewed in Geomini et al., 2009) [18]. Most studies reported an increased diagnostic accuracy and performance with an RMI cut-off of $200[6,16,19,20,22,24,26-32]$. A recent study reported a sensitivity of $89.5 \%$, specificity of $96.2 \%$, positive predictive value of $77.3 \%$, and negative predictive value of $98.4 \%$ [11], when a higher RMI cut-off of 238 was used for the screening. Yamamoto et al. (2009) [25] reported a sensitivity and specificity of $75 \%$ and $91 \%$, respectively, using a cut-off of 450 . The best performance in the present study was seen with an RMI cut-off of 250, and the low sensitivity (54.5\%) and high specificity (93.4\%) observed were comparable to the majority of earlier reports that employed a similar cut-off $[6,19,20,22,26,29-35]$.

We conclude that, in the absence of a definitive biomarker, the multiparametric Risk of Malignancy Index serves as a very useful tool for identification of malignant ovarian disease and their prompt triage and referral to expert care.

\section{Conflict of Interests}

The authors declare that there is no conflict of interests regarding the publication of this paper.

\section{References}

[1] A. Jemal, R. Siegel, J. Xu, and E. Ward, "Cancer statistics, 2010," CA Cancer Journal for Clinicians, vol. 60, no. 5, pp. 277-300, 2010.

[2] J. Ferlay, I. Soerjomataram, M. Ervik et al., "Cancer incidence and mortality worldwide: IARC Cancer Base No. 11," in GLOBOCAN 2012 v1.0, International Agency for Research on Cancer, Lyon, France, 2013, http://globocan.iarc.fr.

[3] Breakaway: The Global Burden of Cancer-Challenges and Opportunities, The Economist Intelligence Unit, London, UK, 2009.

[4] L. McGowan, "Patterns of care in carcinoma of the ovary," Cancer, vol. 71, no. 2, pp. 628-633, 1993.

[5] R. E. Bristow, R. S. Tomacruz, D. K. Armstrong, E. L. Trimble, and F. J. Montz, "Survival effect of maximal cytoreductive surgery for advanced ovarian carcinoma during the platinum era: a meta-analysis," Journal of Clinical Oncology, vol. 20, no. 5, pp. 1248-1259, 2002.

[6] I. Jacobs, D. Oram, J. Fairbanks, J. Turner, C. Frost, and J. G. Grudzinskas, "A risk of malignancy index incorporating CA 125, ultrasound and menopausal status for the accurate preoperative diagnosis of ovarian cancer," British Journal of Obstetrics and Gynaecology, vol. 97, no. 10, pp. 922-929, 1990.

[7] Royal College of Obstetricians and Gynaecologists, "Management of suspected ovarian masses in premenopausal women," RCOG/BSGE Joint Guideline, Royal College of Obstetricians and Gynaecologists, 2011, http://bogs.org.in/RCOG_Guideline_ Sukumar_Barik.pdf.

[8] A. Agarwal, B. J. D. Rein, S. Gupta, R. Dada, J. Safi, and C. Michener, "Potential markers for detection and monitoring of ovarian cancer," Journal of Oncology, vol. 2011, Article ID 475983, 17 pages, 2011.

[9] N. Akdeniz, U. Kuyumcuoğlu, A. Kale, M. Erdemoğlu, and F. Caca, "Risk of malignancy index for adnexal masses," European Journal of Gynaecological Oncology, vol. 30, no. 2, pp. 178-180, 2009.

[10] M. A. Roett and P. Evans, "Ovarian cancer: an overview," American Family Physician, vol. 80, no. 6, pp. 609-616, 2009.

[11] T. Ashrafgangooei and M. Rezaeezadeh, "Risk of malignancy index in preoperative evaluation of pelvic masses," Asian Pacific Journal of Cancer Prevention, vol. 12, no. 7, pp. 1727-1730, 2011.

[12] Z. Bouzari, S. A. Yazdani, M. H. Ahmadi et al., "Comparison of three malignancy risk indices and CA-125 in the preoperative evaluation of patients with pelvic masses," BMC Research Notes, vol. 4, article 206, 2011.

[13] J. M. Escudero, J. M. Auge, X. Filella, A. Torne, J. Pahisa, and R. Molina, "Comparison of serum human epididymis protein 
4 with cancer antigen 125 as a tumor marker in patients with malignant and nonmalignant diseases," Clinical Chemistry, vol. 57, no. 11, pp. 1534-1544, 2011.

[14] E. R. Myers, L. A. Bastian, L. J. Havrilesky et al., "Management of adnexal mass," Evidence Report/Technology Assessment, no. 130, pp. 1-145, 2006.

[15] H. S. Simsek, A. Tokmak, E. Ozgu et al., "ole of a risk of malignancy index in clinical approaches to adnexal masses," Asian Pacific Journal of Cancer Prevention, vol. 15, no. 18, pp. 7793-7797, 2014.

[16] J. H. Rao, "Risk of malignancy index in assessment of pelvic mass," International Journal of Biomedical Research, vol. 5, no. 3, pp. 184-186, 2014.

[17] A. P. Davies, I. Jacobs, R. Woolas, A. Fish, and D. Oram, "The adnexal mass: benign or malignant? Evaluation of a risk of malignancy index," British Journal of Obstetrics and Gynaecology, vol. 100, no. 10, pp. 927-931, 1993.

[18] P. Geomini, R. Kruitwagen, G. L. Bremer, J. Cnossen, and B. W. J. Mol, "The accuracy of risk scores in predicting ovarian malignancy: a systematic review," Obstetrics and Gynecology, vol. 113, no. 2, pp. 384-394, 2009.

[19] S. Ma, K. Shen, and J. Lang, "A risk of malignancy index in preoperative diagnosis of ovarian cancer," Chinese Medical Journal, vol. 116, no. 3, pp. 396-399, 2003.

[20] A. P. Manjunath, K. Sujatha, and R. Vani, "Comparison of three risk of malignancy indices in evaluation of pelvic masses," Gynecologic Oncology, vol. 81, no. 2, pp. 225-229, 2001.

[21] N. Asif, A. Sattar, M. M. Dawood, T. Rafi, M. Aamir, and M. Anwar, "Pre-operative evaluation of ovarian mass: risk of malignancy index," Journal of the College of Physicians and Surgeons Pakistan, vol. 14, no. 3, pp. 128-131, 2004.

[22] B. R. Obeidat, Z. O. Amarin, J. A. Latimer, and R. A. Crawford, "Risk of malignancy index in the preoperative evaluation of pelvic masses," International Journal of Gynecology and Obstetrics, vol. 85, no. 3, pp. 255-258, 2004.

[23] S. Leelahakorn, S. Tangjitgamol, S. Manusirivithaya, P. Thongsuksai, P. Jaroenchainon, and C. Jivangkul, "Comparison of ultrasound score, CA125, menopausal status, and risk of malignancy index in differentiating between benign and borderline or malignant ovarian tumors," Journal of the Medical Association of Thailand, vol. 88, no. 2, pp. S22-S30, 2005.

[24] S. Ulusoy, O. Akbayir, C. Numanoglu, N. Ulusoy, E. Odabas, and A. Gulkilik, "The risk of malignancy index in discrimination of adnexal masses," International Journal of Gynecology and Obstetrics, vol. 96, no. 3, pp. 186-191, 2007.

[25] Y. Yamamoto, R. Yamada, H. Oguri, N. Maeda, and T. Fukaya, "Comparison of four malignancy risk indices in the preoperative evaluation of patients with pelvic masses," European Journal of Obstetrics Gynecology and Reproductive Biology, vol. 144, no. 2, pp. 163-167, 2009.

[26] S. Tingulstad, B. Hagen, F. E. Skjeldestad et al., "Evaluation of a risk of malignancy index based on serum CA125, ultrasound findings and menopausal status in the pre-operative diagnosis of pelvic masses," BJOG: An International Journal of Obstetrics \& Gynaecology, vol. 103, no. 8, pp. 826-831, 1996.

[27] G. Morgante, A. La Marca, A. Ditto, and V. de Leo, "Comparison of two malignancy risk indices based on serum CA125, ultrasound score and menopausal status in the diagnosis of ovarian masses," BJOG: An International Journal of Obstetrics \& Gynaecology, vol. 106, no. 6, pp. 524-527, 1999.

[28] J. C. C. Torres, S. F. M. Derchain, A. Faundes, R. C. Gontijo, E. Z. Martinez, and L. A. L. A. Andrade, "Risk-of-malignancy index in preoperative evaluation of clinically restricted ovarian cancer," Sao Paulo Medical Journal, vol. 120, no. 3, pp. 72-76, 2002.

[29] E. S. Andersen, A. Knudsen, P. Rix, and B. Johansen, "Risk of malignancy index in the pre-operative evaluation of patients with adnexal masses," Gynecologic Oncology, vol. 90, no. 1, pp. 109-112, 2003.

[30] Y. N. Chia, D. E. Marsden, G. Robertson, and N. F. Hacker, "Triage of ovarian masses," Australian and New Zealand Journal of Obstetrics and Gynaecology, vol. 48, no. 3, pp. 322-328, 2008.

[31] W. Moolthiya and P. Yuenyao, "The risk of malignancy index (RMI) in diagnosis of ovarian malignancy," Asian Pacific Journal of Cancer Prevention, vol. 10, no. 5, pp. 865-868, 2009.

[32] M. Terzić, J. Dotlić, I. L. Ladjević, J. Atanacković, and N. Ladjević, "Evaluation of the risk malignancy index diagnostic value in patients with adnexal masses," Vojnosanitetski Pregled, vol. 68, no. 7, pp. 589-593, 2011.

[33] S. Tingulstad, B. Hagen, F. E. Skjeldestad, T. Halvorsen, K. Nustad, and M. Onsrud, "The risk of malignancy index to evaluate potential ovarian cancers in local hospitals," Obstetrics and Gynecology, vol. 93, no. 3, pp. 448-452, 1999.

[34] H. A. Tanriverdi, H. Sade, V. Akbulut, A. Barut, and Ü. Bayar, "Clinical and ultrasonographic evaluation of pelvic masses," Journal of the Turkish German Gynecology Association, vol. 8, no. 1, pp. 67-70, 2007.

[35] O. Meray, I. Türkçüoğlu, M. M. Meydanlı, and A. Kafkaslı, "Risk of malignancy index is not sensitive in detecting non-epithelial ovarian cancer and borderline ovarian tumor," Journal of the Turkish German Gynecological Association, vol. 11, no. 1, pp. 2226, 2010. 


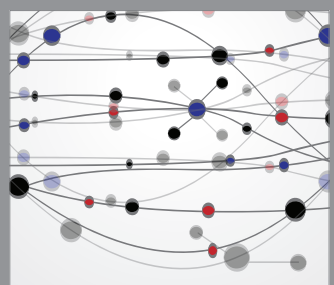

The Scientific World Journal
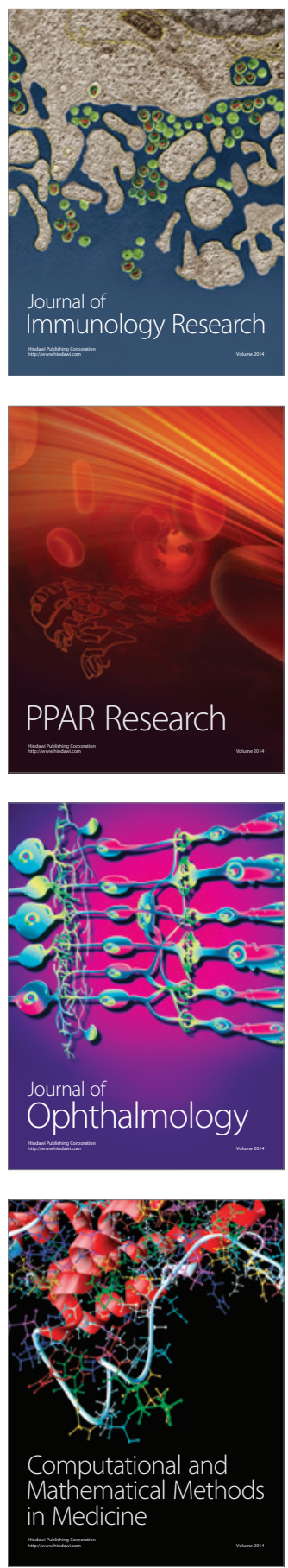

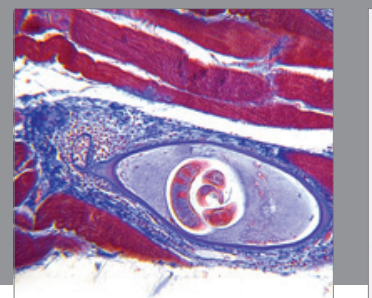

Gastroenterology

Research and Practice
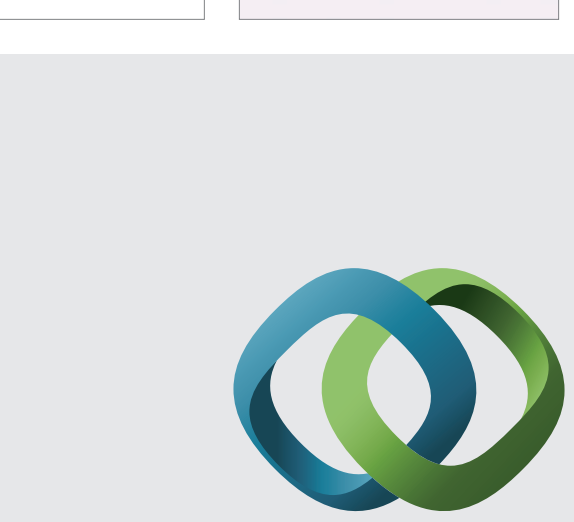

\section{Hindawi}

Submit your manuscripts at

http://www.hindawi.com
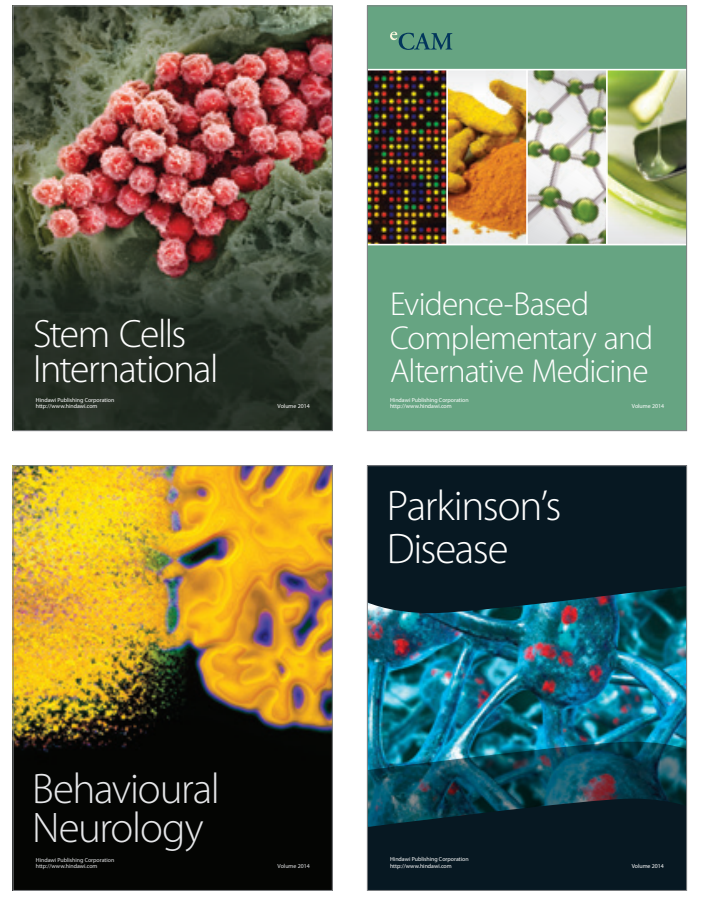
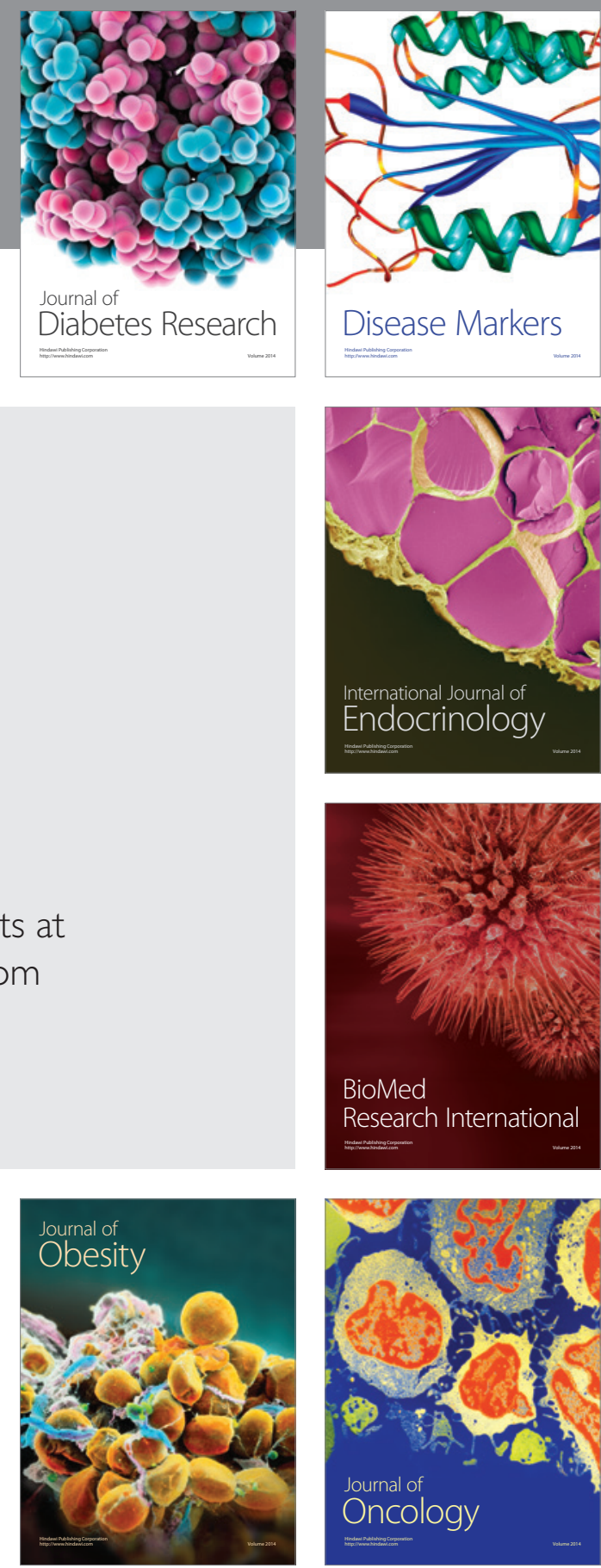

Disease Markers
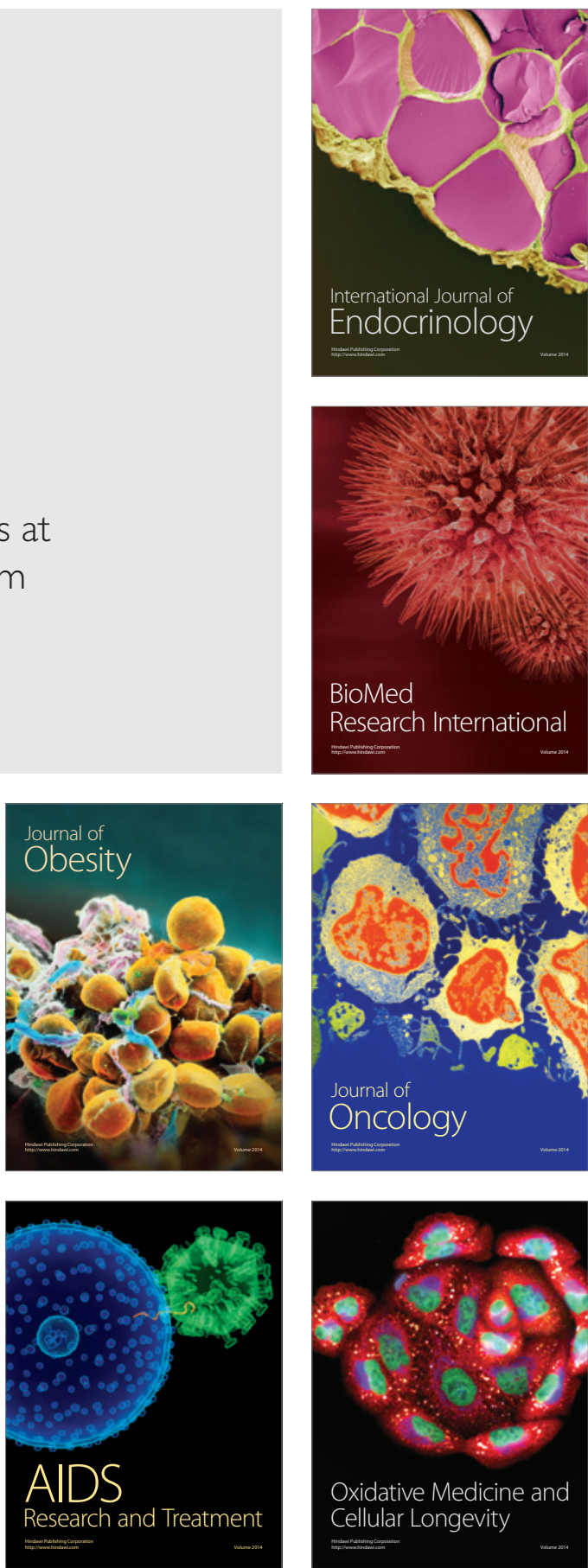